Cite as: L. Corey et al., Science

10.1126/science.abc5312 (2020).

\title{
A strategic approach to COVID-19 vaccine R\&D
}

\author{
By Lawrence Corey ${ }^{1,2}$, John R. Mascola ${ }^{3}$, Anthony S. Fauci ${ }^{4}$, Francis S. Collins ${ }^{5}$ \\ ${ }^{1}$ Vaccine and Infectious Disease Division, Fred Hutchinson Cancer Research Center, Seattle, WA 98109, USA. ${ }^{2}$ Departments of Medicine and Lab Medicine, \\ University of Washington, Seattle, WA 98195, USA. ${ }^{3}$ Vaccine Research Center, National Institute of Allergy and Infectious Diseases, National Institutes of Health, \\ Bethesda, MD 20892, USA. ${ }^{4}$ National Institute of Allergy and Infectious Diseases, National Institutes of Health, Bethesda, MD 20892, USA. ${ }^{5} \mathrm{National}$ Institutes of \\ Health, Bethesda, MD 20892, USA. \\ Email: afauci@niaid.nih.gov

\section{A public-private partnership and platform for harmonized clinical trials aims to accelerate licensure and distribution.}

There is an unprecedented need to manufacture and distribute enough safe and effective vaccine to immunize an extraordinarily large number of individuals in order to protect the entire global community from the continued threat of morbidity and mortality from severe acute respiratory syndrome-coronavirus 2 (SARS-CoV-2). The global need for vaccine and the wide geographic diversity of the pandemic require more than one effective vaccine approach. Collaboration will be essential among biotechnology and pharmaceutical companies, many of which are bringing forward a variety of vaccine approaches (1). The full development pathway for an effective vaccine for SARS-CoV-2 will require that industry, government, and academia collaborate in unprecedented ways, each adding their individual strengths. We discuss one such collaborative program that has recently emerged: the ACTIV (Accelerating COVID-19 Therapeutic Interventions and Vaccines) public-private partnership. Spearheaded by the U.S. National Institutes of Health (NIH), this effort brings together the strengths of all sectors at this time of global urgency. We further discuss a collaborative platform for conducting harmonized, randomized controlled vaccine efficacy trials. This mechanism aims to generate essential safety and efficacy data for several candidate vaccines in parallel, so as to accelerate the licensure and distribution of multiple vaccine platforms and vaccines to protect against COVID-19 (coronavirus disease 2019).

We currently know little about what constitutes a protective immune response against COVID-19. Data from SARS-CoV-1 patients as well as recently infected SARS-CoV2 patients document relatively high levels of immune responses after infection, especially antibody responses to the surface (spike) protein that mediates entry into host cells. However, in vivo data on the type or level of immunity required to protect from subsequent re-infection, and the likely duration of that protection, are currently unknown. In animal models of SARS-CoV-1, immunization with recombinant subunit proteins and viral- and nucleic acid-vectored vaccines, as well as passive transfer of neutralizing antibod- ies to the spike protein, have been shown to be protective against experimental infection $(2,3)$. Endpoints vary from protection of infection to modification of viral replication and disease. These data bring optimism that a highly immunogenic vaccine will elicit the magnitude and quality of antibody responses required for protection. The role that $\mathrm{T}$ cell immunity plays in preventing acquisition or amelioration of early disease, either in animal challenge models or in human coronavirus disease, is unclear (4); this constitutes another reason why a diversity of vaccine approaches must be pursued.

A high degree of safety is a primary goal for any widely used vaccine, and there is theoretical risk that vaccination could make subsequent SARS-CoV-2 infection more severe. This has been reported for feline coronaviruses and has been observed in some vaccine-challenge animal models of SARS-CoV-1 (5). These preclinical data suggest that the syndrome of vaccine-associated enhanced respiratory disease results from a combination of poorly protective antibodies that produce immune complex deposition together with a $\mathrm{T}$ helper cell $2\left(\mathrm{~T}_{\mathrm{H}} 2\right)$-biased immune response. The potential mechanism behind vaccine-induced immune enhancement and the means to minimize this risk have recently been reviewed (6). It will be important to construct conformationally correct antigens to elicit functionally effective antibodies-a lesson learned from vaccine-induced enhanced lower respiratory illness among infants receiving a formalin-inactivated respiratory syncytial virus (RSV) vaccine. Animal models of SARS-CoV-2 infection are currently being developed, and these models can be used to better understand the immune responses associated with protection (7).

\section{CLINICAL AND IMMUNOLOGICAL ENDPOINTS}

The primary endpoint for defining the effectiveness of a COVID vaccine also requires discussion. The two most commonly mentioned are (i) protection from infection as defined by seroconversion, and (ii) prevention of clinically 
symptomatic disease, especially amelioration of disease severity, including the frequency of disease requiring highintensity medical care with some assessment of a decrease in hospitalization. This requires the close evaluation of the effect of vaccination on the severity of COVID-19 disease in a wide variety of epidemiological and medical settings among both younger and elderly populations as well as underserved minorities. All of these issues need to be evaluated in the context of these initial efficacy trials. Achieving these endpoints could also be associated with reduced transmissibility on a population basis.

Primary endpoints that involve reduction of disease require greater numbers of enrollees into trials, given that asymptomatic infection is estimated to be 20 to $40 \%$ of total cases of COVID-19 (8). Initial efficacy trials may then require a large initial enrollment, with ongoing monitoring of both serologic and clinical endpoints. A major challenge leading to a degree of complexity in developing clinical trial protocols for serological endpoints is the lack of precise knowledge of incidence rates (9). A critical requirement for such a multi-trial strategy is the establishment of independent laboratories with similar or identical validated serologic assays to provide a harmonizing bridge between multiple vaccine products and multiple vaccine efficacy trials. The use of these laboratories for each clinical trial, or the sharing of critical specimens from a trial, should be required. Parameters that would distinguish the immune response resulting from vaccination versus from infection are under intense investigation, and there is an immediate need to develop assays to address this issue.

Efficacy trials need to be evaluated for both benefit and harm. The likelihood of SARS-CoV-2 reexposure is much higher than that of SARS-CoV-1, which has disappeared from community circulation, and hence longer-term evaluation of potential enhancement with reexposure is needed. This requirement does not preclude licensure based on the endpoints outlined above; however, it does indicate that more prolonged follow-up of the initial vaccine cohorts should be undertaken. The durability of clinical and serologic endpoints will also need to be explored, as waning of immunity is common with human coronavirus infections (10). Coronaviruses have a single-stranded RNA genome with a relatively high mutation rate. Although there has been some genetic drift during the evolution of the SARSCoV-2 epidemic, major alterations in the spike protein are not extensive to date, especially in the regions thought to be important for neutralization; this enables cautious optimism that vaccines designed now will be effective against circulating strains 6 to 12 months in the future (11).

The possibility of performing controlled human challenge trials, in which a small number of volunteers are vaccinated and subsequently challenged with SARS-CoV-2, has been suggested. Such experiments, if designed to define potential immune correlates or winnow out less effective vaccine approaches, may have utility. However, this approach has shortcomings with respect to pathophysiology and safety (12). Although the risk of severe disease or death in young healthy individuals from COVID-19 is quite low, it is not zero, and we do not yet have proven effective therapies for COVID-19 to rescue volunteers with complications from such a challenge. It is likely that a SARS-CoV-2 challenge strain will, by design, cause mild illness in most volunteers and thus may not recapitulate the pulmonary pathophysiology seen in some patients. Moreover, partial efficacy in young healthy adults does not predict similar effectiveness among older adults with major cofactors associated with COVID-19 disease, nor would it prove reduction of transmissibility to major susceptibility groups. Whether such experiments may be worthy of pursuit or would have a beneficial impact on timelines for vaccine development needs careful evaluation by an independent panel of ethicists, clinical trialists, and experts on vaccine development.

\section{VACCINE PLATFORMS}

It is encouraging that vaccine development efforts have moved swiftly, and several major vaccine platforms are moving toward clinical evaluation. These include traditional recombinant protein, replicating and nonreplicating viral vectors, and nucleic acid DNA and mRNA approaches. Each of these vaccine platforms has advantages and limitations. Important characteristics include speed and flexibility of manufacture, safety and reactogenicity, the profile of humoral and cellular immunogenicity, durability of immunity, scale and cost of manufacturing, vaccine stability, and cold chain requirements. No single vaccine or vaccine platform alone is likely to meet the global need, and so a strategic approach to the multi-pronged endeavor is absolutely critical.

Several companies are developing nucleic acid-based vaccines, including Moderna, BioNTech/Pfizer, CureVac (mRNA-based), and Inovio (DNA-based). DNA- and mRNAbased vaccines can be generated quickly on the basis of viral sequence, which allows a rapid pathway to the clinic (13, 14). Currently, optimal immunogenicity of DNA requires an electroporation or an injector delivery device to facilitate DNA entry into cells. mRNA vaccines use lipid nanoparticles to protect and deliver the mRNA and effectively adjuvant the immunogen. The scalability of these lipid nanoparticles and their temperature stability are issues that need to be addressed. Although there is a wide body of early-phase clinical experience with nucleic acid vaccines, none are licensed for widespread usage. As such, the path forward is filled with optimism, but some uncertainty remains, requiring rapid assessment of these products' immunogenicity and 
safety while addressing the lack of commercial experience with them.

Traditional recombinant protein technology can be used to express the spike protein (e.g., Sanofi, Novavax), and although the time to establish cell lines needed for manufacturing is longer than for nucleic acid vaccines, there is a robust commercial experience with protein and protein particle vaccines, including licensed vaccines for hepatitis B, human papillomavirus, varicella zoster, and influenza. Protein vaccines will require a potent adjuvant, which can be critical for inducing a predominantly $\mathrm{T}_{\mathrm{H}} 1$-type immune response; however, the availability of certain adjuvants may be limited. Viral vector vaccines encode the viral gene of interest into one of several well-characterized vectors, including adenovirus (Ad) and vesicular stomatitis virus (VSV). The replication-defective adenovirus 26 (rAd26), recently shown to be effective in preventing Ebola virus infection (15), is being developed by Janssen Pharmaceuticals for COVID-19. This platform has the potential to be manufactured at large scale. Preexisting immunity to the specific viral vector can attenuate immunogenicity, and this needs to be addressed in early-stage trials. A recombinant chimpanzee Ad vector (ChAdOx1), developed by the University of Oxford and AstraZeneca, has also entered clinical trials. Similar versions of ChAd vaccine products have been tested in prior clinical trials and shown to be safe and immunogenic. The VSV vector vaccine platform is replicationcompetent and thus induces a robust, likely durable immune response with a single dose. A licensed VSV Ebola vaccine made by Merck is highly effective after a single dose, although its reactogenicity may be limiting in some populations. These diverse approaches provide the potential for scalable production required for widespread population use.

\section{STRATEGIC COLLABORATIONS}

Under the ACTIV public-private partnership, NIH has partnered with its sister agencies in the Department of Health and Human Services, including the Food and Drug Administration, Centers for Disease Control and Prevention, and Biomedical Advanced Research and Development Authority; other U.S. government departments including the Departments of Defense and Veterans Affairs; the European Medicines Agency; and representatives from academia, philanthropic organizations, more than 15 biopharmaceutical companies, and the Foundation for NIH. This forum allows for discussions and consensus on vaccine trial designs, rapid data sharing, and close collaborations between the public and private sectors to rapidly and efficiently conduct vaccine efficacy studies. There is an emerging consensus that vaccine trials need to either use common independent laboratories or contribute samples and data for the purpose of generating surrogate markers that ultimately speed licensure and an overall comparison of efficacy. A common Institutional Review Board as well as a common cross-trial Data and Safety Monitoring Board (DSMB) should be used so that the regulatory framework for the entire enterprise is coordinated and the regulatory agencies and the public can make objective assessment of the effect sizes between approaches. As vaccine candidates are poised to enter phase 1, the collective planning for phase 3 must be undertaken. Although much of this focus is on trials in the United States, the COVID-19 Prevention Networks established under the ACTIV program have a global focus, and coordination with the World Health Organization, Coalition for Epidemic Preparedness Innovations, and other global philanthropic partners must also occur.

Harmonized master protocols will be needed to enable transparent evaluation of the relative effectiveness of each vaccine approach. This harmonization can best be achieved through public-private partnerships such as ACTIV, in which government-supported central laboratories and independent biostatisticians serve as key resources for efficacy trials, thereby providing a standardized way to assess the relative immune responses of different types of vaccines (see the figure). Such laboratories enhance the ability to define correlates of protection, which would speed licensure for all vaccines as well as define populations that will achieve protective immunity. Data should be shared among companies and be provided to independent statistical evaluation, allowing the early evaluation of a potential surrogate marker of protection, which would markedly speed licensure and distribution. Such data can only be obtained from harmonization and collaboration early on, during the planning of efficacy trials and the implementation of the collaboration described in the figure: the use of collaborating clinical trial sites, the monitoring of these efficacy trials through a common DSMB, independent statisticians having access to cross-trial data in real time, and centralized immune monitoring laboratories. These innovations in the process of vaccine development are required to achieve the rapid development of the platform technologies entering clinical trials. Global effort, global cooperation, and transparency are needed to maximize the speed, veracity, and decisionmaking required to deliver scientific advances to the global population in a timely fashion. Models for all of these programs exist, and rapid implementation of these ideas is essential if we are to succeed in the timelines required to return us to pre-COVID-19 social interactions.

\section{SCALE UP}

The ability to manufacture hundreds of millions to billions of doses of vaccine requires the vaccine-manufacturing capacity of the entire world. Although new technologies and 
factories can be developed to sustain production, there is an immediate need to fund the necessary biomanufacturing infrastructure, including the fill/finish steps that provide vialed vaccine products for distribution. Cost, distribution system, cold chain requirements, and delivery of widespread coverage are all potential constriction points in the eventual delivery of vaccines to individuals and communities. All of these issues require global cooperation among organizations involved in health care delivery and economics.

To return to a semblance of previous normality, the development of SARS-CoV-2 vaccines is an absolute necessity. To achieve this goal, all the resources in the public, private, and philanthropic sectors need to participate in a strategic manner. The ACTIV public-private partnership and collaborative harmonized efficacy trials are enabling models to achieve our common goal.

\section{REFERENCES AND NOTES}

1. N. Lurie, M. Saville, R. Hatchett, J. Halton, Developing Covid-19 Vaccines at Pandemic Speed. N. Engl. J. Med. 10.1056/NEJMp2005630 (2020). doi:10.1056/NEJMp2005630 Medline

2. J. ter Meulen, A. B. H. Bakker, E. N. van den Brink, G. J. Weverling, B. E. E. Martina, B. L. Haagmans, T. Kuiken, J. de Kruif, W. Preiser, W. Spaan, H. R. Gelderblom, J. Goudsmit, A. D. M. E. Osterhaus, Human monoclonal antibody as prophylaxis for SARS coronavirus infection in ferrets. Lancet 363, 2139-2141 (2004). doi:10.1016/S0140-6736(04)16506-9 Medline

3. H. Bisht, A. Roberts, L. Vogel, A. Bukreyev, P. L. Collins, B. R. Murphy, K. Subbarao, B. Moss, Severe acute respiratory syndrome coronavirus spike protein expressed by attenuated vaccinia virus protectively immunizes mice. Proc. Natl. Acad. Sci. U.S.A. 101, 6641-6646 (2004). doi:10.1073/pnas.0401939101 Medline

4. J. Huang, Y. Cao, J. Du, X. Bu, R. Ma, C. Wu, Priming with SARS CoV S DNA and boosting with SARS CoV S epitopes specific for $\mathrm{CD} 4^{+}$and $\mathrm{CD} 8^{+} \mathrm{T}$ cells promote cellular immune responses. Vaccine 25, 6981-6991 (2007). doi:10.1016/j.vaccine.2007.06.047 Medline

5. M. Bolles, D. Deming, K. Long, S. Agnihothram, A. Whitmore, M. Ferris, W. Funkhouser, L. Gralinski, A. Totura, M. Heise, R. S. Baric, A double-inactivated severe acute respiratory syndrome coronavirus vaccine provides incomplete protection in mice and induces increased eosinophilic proinflammatory pulmonary response upon challenge. J. Virol. 85, 12201-12215 (2011). doi:10.1128/JVI.06048-11 Medline

6. B. S. Graham, Rapid COVID-19 vaccine development. Science 10.1126/science.abb8923 (2020). doi:10.1126/science.abb8923

7. B. Rockx, T. Kuiken, S. Herfst, T. Bestebroer, M. M. Lamers, B. B. Oude Munnink, D. de Meulder, G. van Amerongen, J. van den Brand, N. M. A. Okba, D. Schipper, P. van Run, L. Leiiten, R. Sikkema, E. Verschoor, B. Verstrepen, W. Bogers, J. Langermans, C. Drosten, M. Fentener van Vlissingen, R. Fouchier, R. de Swart, M. Koopmans, B. L. Haagmans, Comparative pathogenesis of COVID-19, MERS, and SARS in a nonhuman primate model. Science 368, eabb7314 (2020). doi:10.1126/science.abb7314 Medline

8. T. M. McMichael, D. W. Currie, S. Clark, S. Pogosjans, M. Kay, N. G. Schwartz, J. Lewis, A. Baer, V. Kawakami, M. D. Lukoff, J. Ferro, C. Brostrom-Smith, T. D. Rea, M. R. Sayre, F. X. Riedo, D. Russell, B. Hiatt, P. Montgomery, A. K. Rao, E. J. Chow, F. Tobolowsky, M. J. Hughes, A. C. Bardossy, L. P. Oakley, J. R. Jacobs, N. D. Stone, S. C. Reddy, J. A. Jernigan, M. A. Honein, T. A. Clark, J. S. Duchin, Epidemiology of Covid-19 in a Long-Term Care Facility in King County, Washington. N. Engl. J. Med. 10.1056/NEJMoa2005412 (2020). doi:10.1056/NEJMoa2005412 Medline
9. S. M. Kissler, C. Tedijanto, E. Goldstein, Y. H. Grad, M. Lipsitch, Projecting the transmission dynamics of SARS-CoV-2 through the postpandemic period. Science 368, eabb5793 (2020). doi:10.1126/science. abb5793 Medline

10. W. Liu, A. Fontanet, P.-H. Zhang, L. Zhan, Z.-T. Xin, L. Baril, F. Tang, H. Lv, W.-C. Cao, Two-year prospective study of the humoral immune response of patients with severe acute respiratory syndrome. J. Infect. Dis. 193, 792-795 (2006). doi:10.1086/500469 Medline

11. T. Bedford et al., Cryptic transmission of SARS-CoV-2 in Washington State. medRxiv 2020.04.02.20051417 [preprint]. 16 April 2020.

12. S. K. Shah, F. G. Miller, T. D. Darton, D. Duenas, C. Emerson, H. Fernandez Lynch, E. Jamrozik, N. S. Jecker, D. Kamuya, M. Kapulu, J. Kimmelman, D. MacKay, M. J. Memoli, S. C. Murphy, R. Palacios, T. L. Richie, M. Roestenberg, A. Saxena, K. Saylor, M. J. Selgelid, V. Vaswani, A. Rid, Ethics of controlled human infection to study COVID-19. Science 10.1126/science.abc1076 (2020). doi:10.1126/science.abc1076

13. K. A. Dowd, S.-Y. Ko, K. M. Morabito, E. S. Yang, R. S. Pelc, C. R. DeMaso, L. R. Castilho, P. Abbink, M. Boyd, R. Nityanandam, D. N. Gordon, J. R. Gallagher, X. Chen, J.-P. Todd, Y. Tsybovsky, A. Harris, Y. S. Huang, S. Higgs, D. L. Vanlandingham, H. Andersen, M. G. Lewis, R. De La Barrera, K. H. Eckels, R. G. Jarman, M. C. Nason, D. H. Barouch, M. Roederer, W.-P. Kong, J. R. Mascola, T. C. Pierson, B. S. Graham, Rapid development of a DNA vaccine for Zika virus. Science 354, 237-240 (2016). doi:10.1126/science.aai9137 Medline

14. N. Pardi, M. J. Hogan, R. S. Pelc, H. Muramatsu, H. Andersen, C. R. DeMaso, K. A. Dowd, L. L. Sutherland, R. M. Scearce, R. Parks, W. Wagner, A. Granados, J. Greenhouse, M. Walker, E. Willis, J.-S. Yu, C. E. McGee, G. D. Sempowski, B. L. Mui, Y. K. Tam, Y.-J. Huang, D. Vanlandingham, V. M. Holmes, H. Balachandran, S. Sahu, M. Lifton, S. Higgs, S. E. Hensley, T. D. Madden, M. J. Hope, K. Karikó, S. Santra, B. S. Graham, M. G. Lewis, T. C. Pierson, B. F. Haynes, D. Weissman, Zika virus protection by a single low-dose nucleoside-modified mRNA vaccination. Nature 543, 248-251 (2017). doi:10.1038/nature21428 Medline

15. I. D. Milligan, M. M. Gibani, R. Sewell, E. A. Clutterbuck, D. Campbell, E. Plested, E. Nuthall, M. Voysey, L. Silva-Reyes, M. J. McElrath, S. C. De Rosa, N. Frahm, K. W. Cohen, G. Shukarev, N. Orzabal, W. van Duijnhoven, C. Truyers, N. Bachmayer, D. Splinter, N. Samy, M. G. Pau, H. Schuitemaker, K. Luhn, B. Callendret, J. Van Hoof, M. Douoguih, K. Ewer, B. Angus, A. J. Pollard, M. D. Snape, Safety and Immunogenicity of Novel Adenovirus Type 26- and Modified Vaccinia AnkaraVectored Ebola Vaccines: A Randomized Clinical Trial. JAMA 315, 1610-1623 (2016). doi:10.1001/jama.2016.4218 Medline

\section{ACKNOWLEDGMENTS}

We thank C. Dieffenbach and E. Erbelding for insightful discussion and comments, and M. Miner for editorial assistance.

Published online 11 May 2020

10.1126/science.abc5312 


\section{The ACTIV model for SARS-CoV-2 vaccine development}

The necessary partners in the public-private partnership are based on nonidentical but harmonized efficacy trials associated with collaborating clinical trials networks and laboratories, a common Data and Safety Monitoring Board, and an independent statistical group to determine correlates of protection.

\begin{tabular}{|c|c|c|c|c|}
\hline \multicolumn{5}{|c|}{ Candidate COVID-19 vaccines } \\
\hline Platform 1 & Platform 2 & Platform 3 & Platform 4 & Platform 5 \\
\hline \multicolumn{5}{|c|}{ Proposed government-supported infrastructure } \\
\hline $\begin{array}{l}\text { Harmonized } \\
\text { efficacy trials }\end{array}$ & $\begin{array}{l}\text { Collaborating } \\
\text { clinical trials } \\
\text { networks }\end{array}$ & $\begin{array}{l}\text { Collaborating labs } \\
\text { - Defining COVID-19 } \\
\text { infections from vaccination } \\
\text { - Quantitative immune } \\
\text { responses to spike and } \\
\text { spike epitopes } \\
\text { - T cell responses }\end{array}$ & $\begin{array}{l}\text { Data and } \\
\text { Safety } \\
\text { Monitoring } \\
\text { Board }\end{array}$ & $\begin{array}{l}\text { Between-trial } \\
\text { statistical } \\
\text { groups for } \\
\text { correlates of } \\
\text { protection }\end{array}$ \\
\hline
\end{tabular}

The ACTIV model for SARS-CoV-2 vaccine development. 